\title{
Are current research funding structures sufficient to address rapid Arctic change in a meaningful way?
}

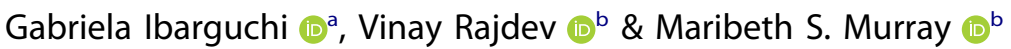 \\ aSan Diego Zoo Institute for Conservation Research, Escondido, CA, USA; ${ }^{b}$ Arctic Institute of North America, University of Calgary, \\ Calgary, AB, Canada
}

\section{ABSTRACT}

Arctic environmental changes already impact regional ecosystems, economies and northern communities, and are having increasing influence on many aspects of the global system. Interest in the Arctic has increased in concert with our improved awareness of potential changes; however, research funding has not necessarily kept pace with the need to improve our understanding of Arctic system change to inform evidence-based decision making. Analyses of data on research funding trends (2003-14) in Canada, the USA and the EU indicate that less than $3 \%$ of the total budget the funding agencies considered is allocated in any given year to Arctic-related research. Furthermore, alignment is uneven among established scientific research priorities, existing societal needs and projects awarded funding. New support mechanisms and improved alignment among resources, expertise and priorities, including Indigenous research priorities, are vital to planning and adaptation in the face of ongoing Arctic change.

\section{KEYWORDS}

Arctic research; funding agencies; environmenta change; North America; European Union; Arctic policy

\section{ABBREVIATIONS}

CIHR: Canadian Institutes of Health Research; EU:

European Union; EU-FP7: 7th Framework Programme; IPY: International Polar Year:

NSERC: Natural Sciences and Engineering Research

Council of Canada; NSF: US National Science

Foundation; SSHRC: Social

Sciences and Humanities

Research Council of Canada

\section{Introduction}

Arctic environmental change is not simply a scientific or regional concern; rather, it is a global issue. The scope and rapid pace of Arctic system change is evidenced by widespread and co-occurring shifts within the biological, physical and human components of the system. Planetary effects, among many, include eustatic sea-level rise resulting from glacier melting and thermal expansion of the oceans, altered weather in the mid-latitudes including potential increases in the intensity and frequency of extreme events, complex cascading ecological shifts, and increased international economic, strategic and political attention to the Arctic (Post et al. 2013; Whiteman et al. 2013; Cohen et al. 2014; IPCC 2014). The consequences of Arctic change are profound, presenting an array of environmental, social, economic, cultural and political challenges, particularly around adaptation and mitigation (Newton et al. 2016), and the achievement of desired ways of life under less than optimal and highly variable, even unpredictable, circumstances (Ford et al. 2015). Here we consider international commitment to addressing Arctic change through support of basic research by examining data on funding trends in Canada, the USA and the EU from 2003 to 2014. Canada, the USA and some member states of the
EU are Arctic nations, and have well-established Arctic research policies, priorities and agencies charged with supporting polar research. Increasingly, non-Arctic states are also developing Arctic policy and priorities around research, development and environmental change.

Research funding structures vary widely among and within countries; support may stem from government programmes and agencies, military departments, foundations, the private sector, special-focus initiatives, individuals or from an amalgamation of sources. In Canada and the USA, research is often funded through large federal funding agencies (e.g., SSHRC, NSERC and CIHR in Canada, and in the US the NSF), and in the EU, through the European Research Council. While other funding agencies exist in North America and in European countries (e.g., the Swedish Research Council), this paper focuses on agencies with accessible and comparable metadata on funding levels and research activities from the years 2003 to 2014, and including the IPY 2007-08. Data from subsequent years for agencies we considered are currently incomplete as in some instances it has yet to be published. Our analysis of funding distribution is also limited by the fact that many agencies simply publish an award distributions list with little metadata (amount of funding, project 
abstract, duration, etc.). Some countries such as China do conduct a significant amount of Arctic research, but it is not possible to locate the metadata that would allow inclusion in our analysis here.

We also did not include funding for research infrastructure, or funds directed towards the operation of infrastructure such as icebreakers or field stations. Infrastructure supports research but it is not research in and of itself. Large investments for research infrastructure do not necessarily translate into equivalent investment in research during the same time as was the case during the IPY. Infrastructure budgets may be apportioned separately from research budgets or buried within the overall budget of an organization or institution. For example, in Canada research infrastructure is largely funded through the Canadian Foundation for Innovation and some infrastructure is supported through the NSERC Major Science Instrumentation programme. Occasionally there are one-time opportunities, such as during the IPY when Aboriginal Affairs and Northern Development Canada offered a one-time Arctic Research Infrastructure Funding programme of 85 million CAD. Infrastructure funding may not be regularly mandated within any one agency, and even if it is, there may be no specific allocation within that budget for Arctic-specific infrastructure.

Where Arctic infrastructure funding might be a regular part of an agency's funding allocation, it can be it is difficult to untangle because of the way in which the data are reported. In Germany, Arctic research is supported by the Federal Ministry of Education and Research through targeted funding and block funding to the Alfred Wegner Institute's Hemholtz Centre for Polar and Marine Research, among others, and through a number of other agencies such as the German Research Foundation, the German Academic Exchange Service, the Federal Ministry for Economic Affairs and Energy and the National Aeronautics and Space Centre. Funds are directed to coordination activities, basic research and infrastructure including vessels, field stations, aircraft and satellites. However, the published budget for the Alfred Wegner Institute, for example, does not specify Arctic, Antarctic or marine and coastal research, and does not distinguish between research and infrastructure spending.

Metadata were available for Canada from the Tri-Council Agencies: NSERC (2016a, b), SSHRC (2016a, b) and the CIHR (2016a, b). For the USA, metadata were available from the NSF $(2016 a, b)$, the principal government agency that funds research, education and training in science, social science and engineering. Metadata were also obtained for the European Commission's
Research and Innovation EU-FP7 (European Commission 2013a, b), which facilitated research collaborations among EU nations. The content of project titles and abstracts was analysed for the keywords arctic, polar and northern for projects funded by these agencies, focusing on Arctic studies in a strict sense, in order to separate Arctic projects or Arctic-relevant projects from all others. For each agency and year (Figs. 1, 2, Table 1), we determined the following: (1) total support for all research; (2) total support for Arctic research; (3) the percentage of the total budget allocated to Arctic research; and (4) proportional allocations of funding in various currency categories to Arctic projects.

\section{Distribution of support for Arctic research}

Only a fraction of the total annual budgets of each of these five agencies was allocated to Arctic researchtypically less than $1.5 \%$ and no greater than $3 \%$ in any year, across disciplines, including during the IPY, and including studies directly related to the Arctic climate itself (Fig. 1, Table 1). From 2008 to 2014, an overall increase in support from the NSF and EU-FP7 was noted (Fig. 1, Table 1). In Canada, from 2003 to 2014, support for Arctic natural sciences and engineering research (NSERC) declined by roughly half, while support for Arctic social sciences (SSHRC) almost tripled (Fig. 1). However, Arctic SSHRC projects were about half the number of NSERC studies, and generally had lower budgets (Fig. 2c, Table 1). A few Arctic health sciences projects were funded in Canada under CIHR ( $<20$ projects per year; Fig. 2c); similar data on Arctic health research were unavailable for the USA or the EU funding agencies we considered; however, it is likely that Arctic human health research is supported through agencies such as the National Institutes of Health (2015). While we continue to analyse the nature of funded research (specific discipline, problem focus, topical area, etc.) through a more detailed content analysis our preliminary results indicate that most research is focused on observation and process studies, modelling and theoretical approaches-very little appears to be solutionoriented.

In Canada, most projects received less than or up to 50000 CAD (Fig. 2c). In contrast, in the USA, there was a higher level of support for most projects (100000 USD or greater), while in the EU, very few projects were funded under the EU-FP7 structure, but most were supported at levels of 100 000 EUR as a minimum, or even 1000000 EUR or greater (Fig. 2a). These diverse strategies for supporting Arctic science may be beneficial when viewed as a collaborative international effort. Funding multiple small projects (e.g., in Canada) 

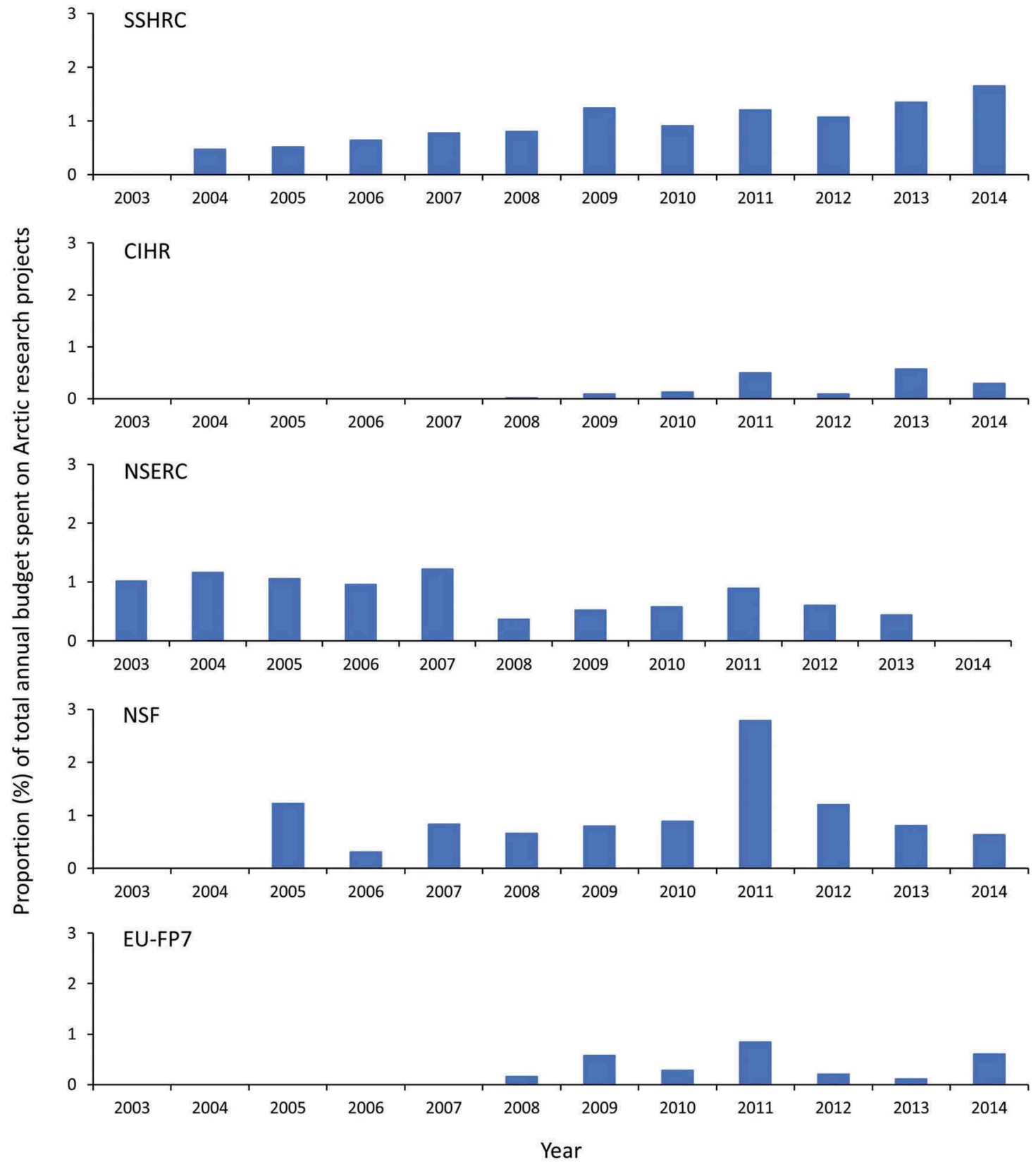

Figure 1. The proportion of total annual budgets spent on Arctic research for each agency considered. Data for NSERC 2014-15 were unavailable.

may provide flexibility and adaptability in the research focus over shorter time frames, while funding a few large projects (e.g., in the EU) may enable international collaboration for longer studies with a pre-defined focus of common interest, providing more sustainability. Beyond basic budgetary constraints, we can speculate also as to why resources are allocated in this way. In the USA, a large portion of the funding awarded may be overhead (indirect costs) charged on direct expenses by institutions to maintain facilities and administration. This rate varies among institutions and can be quite substantial, such as $50.5 \%$ at the University of
Alaska Fairbanks (2018), and 55\% at the University of California Berkeley for on-campus sponsored research $(26 \%$ for off-campus [University of California Berkeley 2018]) at the time of writing. At other institutions in the USA, it may be even higher. In Europe, rates are also variable. In Canada, the Tri-Council agencies generally do not support overhead costs. Thus, in theory, an award in the USA might need to be at least 50\% larger than one in Canada to support the same research simply because of the indirect costs. The way in which researchers are supported by their home institutions can have considerable impacts on 


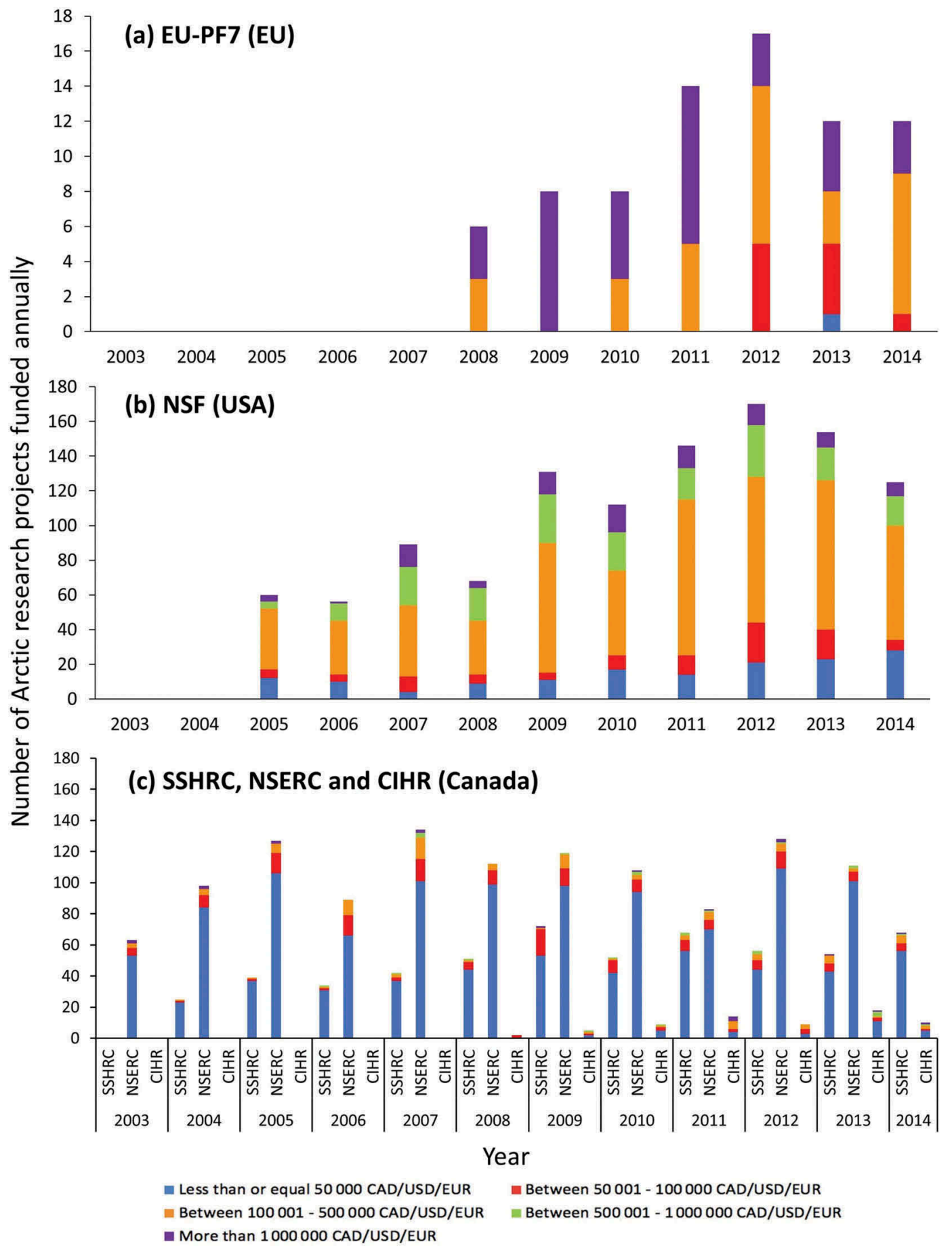

Figure 2. Trends in the distribution of financial resources for Arctic research project. (a) EU (EU-FP7). (b) USA (NSF), (c) Canada (Tri-Council). Note that the $y$ axis is at a different scale for EU-FP7. Data for NSERC 2014-15 were unavailable.

funding requests also, depending upon whether salaries are derived from research funds or are paid out of institutional operational funds.

\section{Policy implications}

International attention to the potential for development around the Arctic is increasing. Despite the risky conditions, summer sea-ice loss has caused great interest in ship transit through the Arctic, for the transport of goods, tourism (Hoag 2009;
Bennett 2014; Shephard et al. 2016) and access to largely unexploited natural resources. At the same time, there are growing concerns about human health and well-being, new pathogens, damage to cultural resources, development, coastal and inland infrastructure and emerging issues related to climate and ecosystem change (Furgal \& Seguin 2006; Dudley et al. 2015). The growing number of questions about a changing Arctic underpin a recent consensus among the scientific community and some northern Indigenous organizations on 
Table 1. Total and Arctic-specific funding allocated by agencies in the USA, the EU and Canada over the past decade. For NSF (USA) and CIHR (Canada), figures for the overall total annual budgets were obtained from annual reports. Figures are shown in millions in the local currency to avoid artefacts from inter-annual variation in exchange rates.

\begin{tabular}{|c|c|c|c|c|c|c|c|c|c|c|}
\hline \multirow[b]{3}{*}{ Year } & \multirow{2}{*}{\multicolumn{2}{|c|}{$\frac{\text { USA (million USD) }}{\text { NSF }}$}} & \multirow{2}{*}{\multicolumn{2}{|c|}{$\begin{array}{c}\text { EU (million EUR) } \\
\text { EU- FP7 }\end{array}$}} & \multicolumn{6}{|c|}{ Canada (million CAD) } \\
\hline & & & & & \multicolumn{2}{|c|}{ NSERC } & \multicolumn{2}{|c|}{ SSHRC } & \multicolumn{2}{|c|}{ ClHR } \\
\hline & Total & Arctic & Total & Arctic & Total & Arctic & Total & Arctic & Total & Arctic \\
\hline $2003-04$ & NA & NA & NA & NA & 697.0 & 7.1 & NA & NA & NA & NA \\
\hline 2004-05 & 5500.0 & 67.1 & NA & NA & 765.6 & 8.9 & 212.2 & 1.0 & NA & NA \\
\hline $2005-06$ & 5650.0 & 17.3 & NA & NA & 820.6 & 8.7 & 252.7 & 1.3 & NA & NA \\
\hline 2006-07 & 5880.0 & 49.2 & 452.5 & 0.0 & 463.0 & 4.4 & 290.4 & 1.9 & NA & NA \\
\hline 2007-08 & 6080.0 & 40.1 & 5571.6 & 9.1 & 968.7 & 11.8 & 305.3 & 2.4 & NA & NA \\
\hline $2008-09$ & 9492.0 & 75.3 & 4713.4 & 27.3 & 980.9 & 3.6 & 344.1 & 2.8 & 956.0 & 0.2 \\
\hline 2009-10 & 6873.0 & 60.8 & 6025.2 & 16.8 & 1003.5 & 5.2 & 323.5 & 4.0 & 922.8 & 0.8 \\
\hline 2010-11 & 6874.0 & 191.8 & 6694.0 & 56.2 & 898.9 & 5.2 & 334.9 & 3.1 & 938.3 & 1.2 \\
\hline 2011-12 & 7033.0 & 84.5 & 7375.0 & 15.6 & 1035.2 & 9.2 & 332.4 & 4.0 & 978.3 & 4.9 \\
\hline $2012-13$ & 6900.0 & 55.8 & 8573.6 & 9.4 & 1021.9 & 6.2 & 339.3 & 3.6 & 965.3 & 0.8 \\
\hline 2013-14 & 7200.0 & 45.5 & 4176.0 & 25.3 & 1018.1 & 4.5 & 337.0 & 4.6 & 956.8 & 5.5 \\
\hline 2014-15 & NA & NA & 135.6 & 0.0 & NA & NA & 338.7 & 5.6 & 950.8 & 2.8 \\
\hline
\end{tabular}

the need for greater support of Arctic research, the development of an internationally supported panArctic observing system (AOS 2016; Murray et al. 2018) and, importantly, Indigenous self-determination in research. And yet, despite the pressures noted above and many others, with some exceptions, over the past decade Arctic research has received a very small $(<3 \%)$ proportion of total funding envelopes. For Canada and the USA, this should be seen as a particularly critical policy issue. Over $76 \%$ of the Canadian land mass is within the sub-Arctic or Arctic biomes (Bone 2012). Roughly one third of Alaska lies north of the Arctic Circle (at about $66^{\circ} 33^{\prime} \mathrm{N}$ ), representing over $21 \%$ of the total area of the contiguous USA. Canada has the longest Arctic coastline in the world and these marine waters, along with Alaska's, are some of the most productive on the planet. Significantly, both countries also contain large reserves of offshore oil and gas. All of the Arctic countries are home to Indigenous peoples, many of whom who have settled land-claims agreements, and all of whom are affected most immediately by Arctic change, along with the residents of low-lying island nations in the Southern Hemisphere. In the EU, the Kingdom of Denmark (including Greenland and the Faroe Islands), Sweden and Finland, all possess large territories north of the Arctic Circle, as does Norway, a country which is not part of the EU but which is included in EU research funding programmes. Many of these countries have produced an Arctic strategy, and the EU has positioned itself as an "Arctic entity" yet the low proportion of funding earmarked for Arctic research lies in contrast to the many issues and potential impacts from change and the size of the territories lying within Arctic boundaries. While it is true that only a small percentage of the Earth's population inhabits the Arctic, the Arctic nations are among the wealthiest, and the rate of change is such that regional and global repercussions are already felt. As a starting point for assessing whether current levels of funding are sufficient, it might be useful to consider the extent which funding for Arctic research or Arcticrelevant research (for example, earth observation and mental health studies) supports national objectives around human and planetary health and sustainability, international agreements around biodiversity, cooperation and peaceful collaboration and Indigenous rights, including poverty reduction and self-determination.

The levels of support for individual projects highlight different approaches to funding and expectations around cooperation and international collaboration. Supporting many projects at lower funding levels as is currently the case in Canada and the USA may increase the type and diversity of research conducted simply because the door is open to more people. For example, one might hope it would facilitate research directed towards addressing Indigenous objectives and priority Arctic themes, but this is difficult to ascertain because of the way the agencies present project metadata. Similarly, it is equally difficult to determine whether access to a larger funding pool enables more innovation, a greater variety of research or improved collaboration among nations. Some types of research are inherently more expensive than others and it is difficult to determine what threshold of support is needed to really accelerate innovation and advance knowledge in national and international contexts. At the 2016 Arctic Observing Summit (AOS 2016; Murray et al. 2018), numbers in excess of 100 million dollars per year were suggested as necessary for the implementation of the pan-Arctic observing system deemed so critical. If this amount were added to the current funding pool, Arctic research investment would still represent only a small fraction of the combined research budgets of the North American, European and other nations with Arctic interests such as China, Korea and Japan. 


\section{Hope on the horizon?}

The 2016 United Nations Climate Change Conference in Marrakech, Morocco, underscored the international consensus on addressing climate change as a global priority. The immediate and future regional and global impacts from ongoing Arctic change, the scientific and societal consensus around the need for greater investment, speak to the potential importance of maintenance of the cryosphere for the planet as a whole (Newton et al. 2016). Funding organizations and vested parties should consider allocating resources and expertise to Arctic research in a more substantive way, and also investment in addressing Indigenous research priorities and information needs. Countries with Arctic interests can undertake a national assessment of their investments across the agencies and councils that support basic research. Then, in partnership with the research community, Indigenous people and entities that have operational responsibilities in the Arctic (for example the Coast Guard or the national weather services) take the necessary steps to align their investments with the research priorities that are collectively established at the national level, and where there is potential for improving international cooperation. This latter activity can be done in conjunction with international initiatives already underway, including the Arctic Observing Summit.

Exploration and discovery are fundamental components of basic research. We are not arguing that resources should not be transferred away from specific disciplines or other region-specific studies. Rather we suggest that additional funding or even the existing funding be prioritized somewhat differently to better align with collectively established priorities. This may be especially important among the countries directly responsible for the vast Arctic territories, and countries hoping to benefit from the opening of Arctic shipping routes for commerce and development, for example, Arctic Council observer states. International cooperation is one way to pool resources and expertise to address common goals, such as a sustained Arctic observing system, although some existing processes and protectionist/nationalist policies within funding agencies may hamper this. The EU provides one example of how this may be managed. The EU policy for the Arctic focuses on three priority areas relating to climate change and the Arctic environment, sustainable development and international cooperation (European Commission 2016) and committed to research, science and innovation that will address these three priority areas. The EU is expected to maintain current fund levels for Arctic research under the Horizon 2020 programme (around 200 million EUR) and has committed to 40 million EUR for the 2016-17 work programme.

Collaborative international Arctic research funding opportunities, such as the Horizon 2020 framework, the Belmont Forum (e.g., 2014 Arctic Belmont Challenge) and others that partner Arctic and nonArctic nations, and scientists and Indigenous people, forcefully demonstrate how such collaborations can catalyse research, but increased flexibility from federal funders would greatly enhance this. The capacity to support Arctic research is great and, given the high stakes, all ongoing efforts to address funding roadblocks are encouraging.

\section{Acknowledgements}

We thank Tommaso Materossi (CODIS Helpdesk, Publications Office of the EU) for providing information on the EU Open Data Portal, S. Craig Gerlach, Karen McCullough, and Ravi Sankar for their comments on an earlier version, and Volker Rachold for guiding us through the German funding landscape. Lastly, we greatly appreciate Robert Newton and an anonymous reviewer for their constructive feedback to improve this manuscript.

\section{Disclosure statement}

No potential conflict of interest was reported by the authors.

\section{Funding}

This work was supported by the US NSF (award no. 0943320) to MM and a University of Calgary Eyes High Post-Doctoral fellowship to GI.

\section{ORCID}

Gabriela Ibarguchi (D) http://orcid.org/0000-0002-44916104

Vinay Rajdev (D) http://orcid.org/0000-0002-5756-7329

Maribeth S. Murray (D) http://orcid.org/0000-0003-28219381

\section{References}

AOS (Arctic Observing Summit) 2016. Arctic Observing Summit: March 15-18, 2016. Fairbanks, Alaska. Accessed on the internet at http://www.arcticobserving summit.org/aos-2016-0 on 21 October 2018.

Bennett M.M. 2014. North by northeast: toward an Asianarctic region. Eurasian Geography and Economics 55, 71-93.

Bone R.M. 2012. The Canadian North: issues and challenges. Don Mills, Ontario: Oxford University Press Canada. 
CIHR (Canadian Institutes of Health Research) 2016a. Canadian Research Information System. Accessed on the internet at http://webapps.cihr-irsc.gc.ca/funding/Search? p_language $=E \& p \_$version $=\mathrm{CIHR}$ on 21 October 2018.

CIHR (Canadian Institutes of Health Research) 2016b. Reports to Parliament: annual reports. Accessed on the internet at http://www.cihr-irsc.gc.ca/e/22978.html on 21 October 2018.

Cohen J., Screen J.A., Furtado J.C., Barlow M., Whittleston D., Coumou D., Francis J., Dethloff K., Entekhabi D., Overland J. \& Jones J. 2014. Recent Arctic amplification and extreme mid-latitude weather. Nature Geoscience 7, 627-637.

Dudley J.P., Hoberg E.P., Jenkins E.J. \& Parkinson A.J. 2015. Climate change in the North American Arctic: a one health perspective. EcoHealth 12, 713-725.

European Commission 2013a. European Union Open Data Portal. CORDIS-EU research projects under Framework Program 7 (FP7, 2007-2013). Accessed on the internet at http://data.europa.eu/euodp/en/data/data set/cordisfp7projects on 21 October 2018.

European Commission 2013b. European Commission, Research and Innovation. Annual and other reports. Accessed on the internet at http://ec.europa.eu/ research/index.cfm?pg=reports on 21 October 2018.

European Commission 2016. An integrated EU policy for the Arctic. Accessed on the internet at https://ec.europa. eu/environment/efe/themes/climate-action/integratedeu-policy-arctic_en on 7 November 2018.

Ford J.D., McDowell G. \& Pearce T. 2015. The adaptation challenge in the Arctic. Nature Climate Change 5, 1046-1053.

Furgal C. \& Seguin J. 2006. Climate change, health, and vulnerability in Canadian Northern Aboriginal communities. Environmental Health Perspectives 114, 1964-1970.

Hoag H. 2009. The cold rush. Nature Biotechnology 27, 690-692.

IPCC (Intergovernmental Panel on Climate Change) 2014. Climate change 2014: synthesis report. Contribution of Working Groups I, II and III to the fifth assessment report of the Intergovernmental Panel on Climate Change. Core Writing Team, R.K. Pachauri \& L.A. Meyer (eds.). Geneva: Intergovernmental Panel on Climate Change.

Murray M.S., Sankar R.D. \& Ibarguchi G. 2018. The Arctic Observing Summit. Background and synthesis of outcomes 2013-2016. Calgary: International Study of Arctic Change Program Office, Arctic Institute of North America.

National Institutes of Health 2015. Grants \& Funding. Accessed on the internet at https://grants.nih.gov/ grants/oer.htm on 21 October 2018.

Newton R., Pfirman S., Schlosser P., Tremblay B., Murray M. \& Pomerance R. 2016. White Arctic vs. blue Arctic: a case study of diverging stakeholder responses to environmental change. Earth's Future 4, 396-405.

NSERC (Natural Sciences and Engineering Research Council of Canada) 2016a. NSERC's awards database. Accessed on the internet at http://www.nserc-crsng.gc. ca/ase-oro/index_eng.asp on 21 October 2018.

NSERC (Natural Sciences and Engineering Research Council of Canada) 2016b. Quarterly financial reports. Accessed on the internet at http://www.nserc-crsng.gc. ca/NSERC-CRSNG/Reports-Rapports/QFR-RFT/index_ eng.asp on 21 October 2018.

NSF (National Science Foundation) 2016a. NSF awards search. Accessed on the internet at https://www.nsf. gov/awardsearch/ on 21 October 2018.

NSF (National Science Foundation) 2016b. NSF budget requests to Congress and annual appropriations. Accessed on the internet at https://www.nsf.gov/about/ budget/ on 21 October 2018.

Post E., Bhatt U.S., Bitz C.M., Brodie J.F., Fulton T.L., Hebblewhite M., Kerby J., Kutz S.J., Stirling I. \& Walker D.A. 2013. Ecological consequences of sea-ice decline. Science 341, 519-524.

Shephard G.E., Dalen K., Peldszus R., Aparicio S., Beumer L., Birkeland R., Gkikas N., Kourantidou M., Ktenas P., Linde P.W., Marazzi F., Pincinato R.B.M., Radianti J., Schartmuller B., Stubner E.I., Varnajot A., Vullierme M. \& Zhilina I. 2016. Assessing the added value of the recent declaration on unregulated fishing for sustainable governance of the central Arctic Ocean. Marine Policy 66, 50-57.

SSHRC (Social Sciences and Humanities Research Council of Canada) 2016a. SSHRC awards engine. Accessed on the internet at http://www.sshrc-crsh.gc.ca/results-resul tats/award_search-recherche_attributions/index-eng. aspx on 21 October 2018.

SSHRC (Social Sciences and Humanities Research Council of Canada) 2016b. Reports and Publications Archive. Accessed on the internet at http://www.sshrc-crsh.gc. ca/about-au_sujet/publications/archive-eng.aspx on 21 October 2018.

University of Alaska Fairbanks 2018. Facilities \& administrative costs. Accessed on the internet at http://www.uaf. edu/ogca/resources/regulations/indirect on 21 October 2018.

University of California Berkeley 2018. Facilities \& administrative (indirect cost) rates. Accessed on the internet at https://spo.berkeley.edu/Policy/fa.html on 21 October 2018.

Whiteman G., Hope C. \& Wadhams P. 2013. Climate science: vast costs of Arctic change. Nature 499, 401-403. 